THURSDAY, JANUARY 5, 1882

\section{ON THE GEOLOGICAL IMPORTANCE OF THE TIDES}

T $\mathrm{T}$ has naturally been a source of much satisfaction to 1 me that a man as able and eloquent as the Astronomer-Royal for Ireland should have come forward as an exponent of the theory which I have advanced concerning the part played by tides in the history of the earth and the other planets. I cannot but feel therefore that it may seem ungracious on my part to appear as a critic, and to ask Mr. Ball to reconsider some of the deductions which he has made in his Birmingham lecture (see NATURE, vol. xxv. pp. 79, I03). I refer to the geological aspects of the theory. The interest - of the subject will, I feel sure, prove a sufficient excuse for my being thus critical.

There is I believe a growing feeling amongst geologists that the extreme uniformitarian view as to geological action requires modification. We find on the one hand the physicist demanding of the geologist that he should hurry on the rate of action, and on the other hand the geologist telling the physicist to moderate his demands. A theory, therefore, which receives much support from purely astronomical considerations concerning the observed configurations of planets and satellites, and which enables geol gists to perceive how the rate of geological action may have been more rapid in the past, is valuable as a means of reconciliation between two apparently opposed branches of science. All this has been admirably insisted on by Mr. Ball, but I think that in the revulsion from uniformitarianism he has passed considerably too far into the ranks of the opposite school.

Accepting the truth of the tidal mode of evolution of the earth and moon, the question at issue is as to what portion of the series of changes, since the birth of the moon, falls within the region of geological history.

In my own paper in discussing this point, I said :

"There are other consequences of interest to geologists which flow from the present hypothesis. As we look at the whole series of changes from the remote past, the ellipticity of figure of the earth must have been continually diminishing, and thus the Polar regions must have been ever rising and the equatorial ones falling; but, as the ocean always followed these changes, they might quite well have left no geological traces.

"The tides must have been very much more frequent and larger, and accordingly the rate of oceanic denudation much accelerated.

"The more rapid alternation of day and night would probably lead to more sudden and violent storms, and the increased rotation of the earth would augment the violence of the trade winds, which in their turn would affect oceanic currents. Thus there would result an acceleration of geological action." I

At the time when I wrote this I contemplated the possibility of the tides having been, in the earliest geological times, ${ }^{2}$ perhaps twice or thrice as high as at present, and

x "Precession of a Viscous Spheroid. \&c.," Phil. Trans. Part 2, 1879, p. 532. It would occupy too much space to reproduce the other comments on the Geological aspects of the theory

${ }^{2}$ A double tide would (in round numbers) correspond to a lunar distance of 48 earth's radii, instead of the present 60 , and to a day of about 16 hours. A double tide gives a quadruple rate of retardation of the earth's rotation. Vor. Xxv.-No. 636
I now feel inclined to consider this estimate rather as excessive than deficient. But Mr. Ball speaks of tides of over 600 feet as having perhaps occurred within geological times, and I would now ask him to reconsider the probability of this view.

The older geologists attributed the larger part of denudation to the action of the sea, but according to the modern, and undoubtedly the more correct opinion, the denuding action of air and rain, with the aid of rivers and their countless affluents, is of far greater importance. $\mathrm{Mr}$. Ball does not allude to the probable increase of rainfall, but it would, I conceive, be quite as important as the direct tidal action.

If the ordinarily received theory of the trade and antitrade winds be correct, it follows that in similar planets, at equal distances from the sun and with the same depth of atmosphere, the velocity of the wind should vary as the linear velocity of a point at the planet's equator. The planet Jupiter rotates $2 \cdot 4$ times as fast as the carth, and has a radius $10 \frac{1}{2}$ times as great; hence if it were not for the greater distance from the sun the trades should blow with 25 times the violence which we observe on the earth. But solar radiation at Jupiter is about $\frac{\pi}{27}$ of that at the earth. Hence if Jupiter had an atmosphere of the same depth as that of the earth, the trade-winds might blow with about the same violence. If however there be a much deeper atmosphere on that planet, then the a mount of solar heat absorbed might be much greater, and the violence of the winds increased. The bands on Jupiter, which are due to the trades and anti-trades, thus afford some evidence that the atmosphere of Jupiter is very deep. It seems, however, quite possible that the violence of the Jovian trades is due partially, or to a great extent, to the heat of the Jovian nucleus.

But now let us return to the case of the earth. The table of numerical values which I have computed ( $O p$. cit. p. 494) shows that, when the lunar distance was ten earth's radii (which gives Mr. Ball's tide of 648 feet), the earth must have been rotating in about seven hours. Accordingly it is probable that the trades and anti-trades blew with about $3 \frac{3}{7}$ their present velocity. This violence of the general atmospheric circulation to and from the equator, coupled with the rapid alternations of day and night, would undoubtedly give rise to vortical storms of prodigious violence.

Now if this state of things existed in geological history we should expect to find the earlier sedimentary rocks of much coarser grain than the modern ones; but I am not aware that this is the case. Again to withstand such blasts, the earliest trees should have trunks of enormous thickness, and their leaves must have been very tough, or they would have been torn to shreds. There see ms to be no reason to suppose that the trees of the carboniferous period present marked peculiarities in these respects.

It is on these grounds that I venture to dissent from Mr. Ball in the geological interpretation to be placed on the tidal theory, and I think we must put these violent phenomena in pregeological periods.

The dispute is, however, only as to the amount of influence, and I cannot learn that geologists are in a position to affirm that in early periods the storms were not say twice as frequent, and the tides twice as high. The 
acceptation of the view, that they were so, would go far to reconcile the discrepant opinions of the geologists and physicists.

There is, as I learn, some slight geological reason for supposing the tides to have been higher in early times, although this interpretation does not seem to have been hitherto attributed to the fact to which I allude. It appears that in the oldest formations there are beds many feet in thickness covered with ripple marks. The preservation of ripples is due to a fortuitous concurrence of causes, and it therefore cannot be asserted positively that if many ripples are preserved the number of ripples formed was great. Such a deduction possesses, however, a considerable degree of probability, and one of the conditions for the formation of many ripples is a great ebb and flow of the tides.

Lyell's interesting observations on the sands in the Bay of Fundy ("Travels in North America," vol. ii. p. 166), where the tide rises tbrough about seventy feet, seem to show that the preservation of superficial marks on sand occurs principally at neap tides, when large areas of sand are exposed for a long time to the sun, after having been covered with water at the spring tide. Now when the tides were twice as high as at present, there must have been 19 or 20 of our present days in the month instead of $27 \frac{1}{3}$ as at present, and there would be about 38 neap tides in the year instead of about 26.

Since writing the above I have seen Mr. Hull's paper on this subject in NATURE (vol, xxv. p. 177). The evidence which he adduces is of much interest, and if geologists should generally come to recognise the necessity of a powerful denuding agency in order to explain the earlier geological phenomena, such an opinion will stand in direct confirmation of the theory which I have advanced. Notwithstanding what Mr. Hull says, I am still inclined to adhere more to the moderate views maintained above, rather than to admit the extended application of the tidal theory to geology for which Mr. Ball contends. I conceive that a very great acceleration of geological action would result from tides of even one-hundredth of the height portrayed by $\mathrm{Mr}$. Ball, when such tides are accompanied by an intensification of meteorological action.

If Mr. Hull had read my papers, he would have seen that a necessary concomitant of these changes has been a secular diminution of the ellipticity of the earth's figure. For example, when the tides were 600 feet in height, the ellipticity must have been about twelve times as great as at present. Now Sir William Thomson will not allow that there can have been any great change in the ellipticity of the earth's figure since the consolidation of the earth (Thomson and Tait's "Nat. Phil." $\S 830$ ).

If this opinion is correct, extended geological action, as resulting from the present series of causes, is absolutely excluded. For myself I am not at present able to see the force of his argument, for various reasons on which it is useless to enter here. But it must be admitted that in any contest between him and me the chances of correctness are enormously on his side.

In conclusion I wish to add that in my first paper I probably attributed too much of the changes in the configuration of the earth and moon to the effect of bodily tidal deformation of the earth's mass. The evidence is strong that such tides are now but small, or even scarcely sensible in amount, and accordingly in all probability the later part of the changes must be attributed almost entirely to the effects of oceanic tidal friction, whilst in the earlier part the tides of the solid or semi-solid matter constituting the planet were the more important. It is remarkable that this view enables us to give a satisfactory account of the inclination of the lunar orbit to the ecliptic, as is shown in a later paper. ${ }^{1}$

\section{G. H. DARWIN}

\section{EXNER ON CEREBRAL LOCALISATION}

Untersuchungen über die Localisation der Functionen in der Grosshirnrinde des Menschen. Von Prof. Sigmund Exner. (Wien, I88I.)

THIS work is an attempt to determine the functions of 1 different parts of the cerebral hemispheres by an examination of the facts of disease alone, independently of physiological experiment. The difficulties which have to be encountered in the solution of the problem by this method are great, and the sources of fallacy numerous. The facts, collected as they must be from the most diverse sources, are not all of the same value, and errors of observation on the score of inaceuracy or incompleteness have to be taken into account and allowed for. The experiments of disease are as a rule rude, and the conditions highly complex. Certain parts of the brain are more liable to disease than others, and one hemisphere more than the other. Besides the lesion actually discovered after death, there may be others not discovered or not discoverable by our present methods, either coincident merely or indirectly connected with the visible lesion; for morbid anatomy and morbid physiology are by no means coextensive. Exactly symmetrical bilateral lesions are extremely rare in disease, and yet such facts are absolutely necessary for the decision of many important questions.

These and many other circumstances render the determination of the functions of the brain from the data of disease alone extremely uncertain, if not impossible. Until the discovery of new experimental methods a few years ago cerebral pathology, except in one or two particulars, chiefly speculative or purely empirical, was practically in a state of chaos. It is only since the introduction of the new doctrines founded on experimental research that the facts of cerebral disease have begun to be investigated and recorded with any approach to scientific accuracy, and order has begun to show itself where formerly all seemed confusion.

Prof. Exner is of opinion that his predecessors have examined the facts of cerebral disease merely with a view of confirming preconceived theories, and have not exercised sufficient discrimination in the selection of the cases they adduce in favour of the propositions they maintain. In this respect particularly he claims superiority over all who have treated the subject before him.

Out of several thousand cases of cerebral disease on record, he has been able to find only 168 instances of

I "On the Secular Changes in the Elements of the Orbit of a Satellite, \&c.," (Phil. Trans., part ii., I880, p. 73r). 